\title{
CITIZENS DEMOCRACY EDUCATION-BASED RELIGIONS AND CULTURES: CONSIDERATION OF DEMOCRACY SCHOOL IN JENEPONTO, INDONESIA
}

\author{
Muhammad Sabri \\ Universitas Islam Negeri (UIN) Alauddin Makassar, Indonesia \\ Email: mohdsabriar@yahoo.co.id
}

Muh. Ikhsan

Institut Agama Islam Negeri (IAIN) Kendari, Indonesia

Email: ichank ar@yahoo.co.id

Ismail Suardi Wekke

Sekolah Tinggi Agama Islam Negeri (STAIN) Sorong, Indonesia

Email: iswekke@gmail.com

Presented In

4th International Conference on Asean Comparative Education Research Network

(Acer-N)

Padang, Indonesia November 30 to December 1, 2016

\begin{abstract}
Democratic transition phenomenon from New Order era to Reform era is always as important subject of study. From the standpoint of democracy, Indonesia is currently at the "crossroads" with three possible options of different consequences. First, it brings us consolidating democracy and peace. Second, it brings us turn around and go back to the old system. Third, it brings us circling aimlessly and occasionally enlivened by social conflicts to $S A R A$ (ethnicity, religion, race, and intergroup). The question is: which direction of democracy are we going to? This article focuses on Sekolah Demokrasi Jeneponto (SDJ/Jeneponto School Democracy) program in Jeneponto South Sulawesi, which took place in 2006-2008. The program held in cooperation of Komunitas Indonesia untuk Demokrasi (KID/Indonesian Community for Democracy) and Melania Foundation, by Netherlands Institute for Multiparty Democracy (NIMD) sponsorship. SDJ program is a citizen of political and democratic education that aims to transform the value, knowledge, and skills the concept of democracy in Indonesia by considering religion and culture. By discussing about democracy, religion, and culture following by training and mastering democracy instrument, its participants were able to actualize themselves by means of theoretical understanding, excavation experience, reflection, and the implementation of democracy within the framework of civil society.
\end{abstract}

Keywords: Democracy, religion, culture, School Democracy Program, civil society. 


\section{Pendahuluan}

"Sistem pemerintahan yang sempurna ialah melaksanakan pemerintahan sendiri dari bawah", ungkapan itu lahir dari sang proklamator Mohammad Hatta yang tertuang di Harian Pikiran Rakyat pada 27 April 1957. Agaknya, tulisan itu menyiratkan sesuatu yang kini sangat populer: demokrasi dan otonomi. Ternyata otonomi hingga tingkat kabupaten/kota seperti yang ada sekarang, merupakan salah satu yang dalam pandangan Hatta penting untuk diterapkan di Indonesia. Otonomi hingga ke kabupaten/kota bagi Hatta merupakan langkah bagi daerah untuk melaksanakan apa yang dikatakannya sebagai "mengurus rumah tangga sendiri dalam arti yang sebenar-benarnya." Sepertinya, untuk Hatta, otonomi memberikan peluang paling besar untuk pelaksanaan dan penyelenggaraan demokrasi dan peningkatan kesejahteraan rakyat secara mandiri.

Ia berangkat dari arti demokrasi. Sejatinya, arti demokrasi adalah pemerintahan rakyat. Pemerintahan rakyat - karena perkembangan masyarakat-mestilah dilakukan melalui perantara wakil-wakil rakyat yang dipilih oleh rakyat. Sebab itu, harus ada keterkaitan erat antara si pemilih dan si terpilih. Keterkaitan ini terasa berkurang apabila "sentralisme" menjadi poros kehidupan bernegara. Apabila demokrasi berarti melaksanakan pemerintahan dari yang diperintah-menurut Hatta-maka demokrasi, dengan sendirinya, tidak sesuai dengan dasar sentralisme. Sehingga di mata sang proklamator, "semakin luas daerah suatu negara, semakin banyak diferensiasi kepentingan hidup, semakin banyak masalah khas dan tipikal yang menyentuh berbagai daerah, yang semuanya itu tak dapat diurus dari pusat pemerintahan negara."

Karena itu, otonomi dapat dipandang sebagai nuktah awal berdemokrasi dan sekaligus medan "perjumpaan" baru antara kekuatan demokrasi melawan kekuatan antidemokrasi. Daerah, sebab itu, menjadi titik penting penentu hidup dan matinya demokrasi. Keberhasilan dan kegagalan demokrasi sangat ditentukan oleh dinamika yang berlangsung di dalam donamika politik lokal. Kegagalan demokrasi di politik lokal mengantar pada kegagalan berdemokrasi di tingkat nasional. Sebaliknya, keberhasilan menyelenggarakan pemerintahan sendiri di daerah membawa kesuksesan berdemokrasi di tingkat nasional. Demokrasi mestilah bermula dari daerah-daerah. Demokrasi haruslah bergerak dari bawah.

Semangat itu kini sedang dipertaruhkan. Sebab, di tengah-tengah pusaran dan gelombang transisi demokrasi di Indonesia pasca reformasi, yang terjadi sesungguhnya bukan semata perubahan dan kemajuan politik fundamental, tetapi juga menyuguhkan tak sedikit problem dan tantangan konsolidasi. Dengan kata lain, transisi demokrasi Indonesia menampilkan pergulatan ketat antara "ide persambungan" dan "basrat perubahan" tentang Indonesia baru.

Itu sebab, reformasi sistem pemerintahan yang sejauh ini berjalan melalui proses desentralisasi lalu menampilkan dua perspektif. Pertama, proses pergeseran itu cenderung dilihat sebagai persoalan ekonomi dan politik semata, terutama ketika identifikasi persoalan dan pemecahan yang disodorkan cenderung menampik dimensi-dimensi sosial budaya. Dengan menggunakan pendekatan budaya dapat dibentuk kesamaan slidaritas (Wekke, 2016). Dalam konteks ini, perubahan ekonomi dan politik sedemikian rupa telah direduksi dengan cara yang begitu sederhana sehingga mengabaikan dimensi sosial dan dimensi budaya dalam proses penciptaan tatanan yang lebih baik. Kedua, reformasi sistem pemerintahan masih menjadi konsep top-down di mana proses pembagian otoritas politiknya masih didasarkan pada konsepsi politik dan kemauan politik pemerintah pusat. Dalam 
konteks ini otoritas lokal belum menjadi praktik aktual yang berlangsung secara dialogis dalam hubungan pusat-daerah.

Demokrasi mengajarkan bahwa kekuasaan politik dalam pemerintahan harus diorganisir melalui arena "masyarakat politik", yakni kompetisi secara terbuka dan sehat di antara aktor politik dan "partisipasi politik" masyarakat sebagai basisnya. Pemerintahan partai yang dibangun dari kompetisi dalam arena masyarakat politik, secara teoretis akan membuat lingkage antara masyarakat dengan sistem politik, memperkuat akuntabilitas penguasa lokal kepada konstituen yang telah memberikan mandatnya, membuat partai politik lebih berakar pada masyarakat. Bahkan dalam urusan pernikahan sekalipun, tetap saja demokrasi menjadi bagian dari unsur tersebut (Wekke, 2014).

Sementara itu, hegemoni negara yang sejauh ini dipraktikkan rezim Orde Baru telah berhasil melumpuhkan secara nyaris sempurna elemen- elemen simbolik lokal. Akibatnya, masyarakat lokal tidak saja kian "terasing" dari nilai-nilai luhur yang dipeluknya, tetapi bahkan kehilangan tokoh-tokoh simboliknya. Penguatan politik lokal atau identitas kultural lokal, karena itu, harus dipahami sebagai salah satu kekuatan perekat integrasi nasional dan energi gerak yang dapat mempercepat proses pembangunan demokrasi. Revitalisasi identitas lokal yang diwujudkan dalam tataran institusi, status, dan peran lalu menjadi penting. Memberi tafsir ulang dan merekonstruksi "lembaga adat" seperti tercermin dalam tradisi Bugis-Makassar tentang panggadakkang (Bugis: Pangngaderreng) misalnya, mesti dilihat dari sudut pandang dan semangat tersebut di atas.

Menjamurnya agenda "pemekaran wilayah" akhir-akhir ini yang dibangun di atas asumsi-asumsi etnisitas yang lebih spesifik merupakan salah satu indikasi penguatan identitas terhadap wacana demokrasi lokal. Kepelbagaian masyarakat Indonesia yang amat kaya akan identitas kelompok etnis, agama, dan budaya membutuhkan carapandang utuh dalam membangun kerangka interaksi politik yang toleran, yang dalam potensinya bisa memperkuat multikulturalisme. Sejatinya, masyarakat Indonesia senantiasa menjadikan budaya sebagai alat untuk memperkuat keberagamaan (Wekke, 2017). Di sini, heterogenitas lalu menjadi sesuatu yang lumrah. Tetapi juga sesuatu yang amat penting. Ia malahan menjadi bagian tak terpisahkan dari makna teknis "bangsa kosmopolitan" yang sesungguhnya. Dari perspektif ini pula, ungkapan yang mengalir dari mulut seorang arif, "betapa indahnya persatuan justeru karena kita telah terlanjur berbeda" kian menemukan momentumnya.

Dalam konteks masyarakat Indonesia, desentralisasi dan otonomi daerah mengisyaratkan adanya pengakuan terhadap pluralitas masyarakat di daerah, dengan memberikan kesempatan kepada masyarakat lokal untuk mengatur diri sendiri melalui local self goverment. Sementara dari segi politik ekonomi, desentralisasi mengandaikan adanya pemencaran kekuasaan (dispersed of power) yang sesuai dengan tuntutan global dewasa ini dan semakin memberikan ruang-ruang penting bagi masyarakat, sembari merumuskan ulang peran negara sebagai agen regulator dan agen administratif. Harapan tersebut di atas jelas masih menyisakan sejumput kesangsian. Sebab, transisi demokrasi merupakan masa genting. Di saat-saat seperti itu, masyarakat terombang-ambing di antara dua karang: masa depan yang tak karuan atau romansa masa lalu yang tampak lebih pasti.

Sementara masa depan nun jauh di sana pun masih lamat-lamat terlihat. Sepiring nasi hari ini memang belum cukup mengenyangkan, tetapi orang kini tak lagi takut untuk berpendapat dan bebas berserikat. Benar, pemberantasan korupsi masih jauh dari kelar. 
Betul, ketamakan para elite negeri menampik banyak kepentingan rakyat sehingga nurani pertiwi tumpul. Tepat, bahwa kebebasan yang diberikan demokrasi dibajak untuk kepentingan-kepentingan sesaat yang justeru berseberangan dengan demokrasi.

Namun itu tidak lantas berarti perlunya kita kembali ke masa totalitarian saat di mana harga manusia ditentukan oleh telunjuk sang penguasa. Justeru, masa lalu menjadi cermin untuk masa depan. Masa lalu memberi pelajaran penting pada masa kini, sebagaimana masa kini yang menentukan masa depan. Kehidupan demokrasi dan kehidupan berdemokrasi kita kini yang akan menentukan kehidupan demokrasi di masa depan. Demokrasi yang kita praktikkan dan alami sekarang memberikan kesempatan untuk merefleksikan masa lalu, mengoreksi masa sekarang, dan melahirkan masa depan.

Di sini, demokrasi menjadi demikian penting dalam perjalanan sejarah bangsa. Hanya melalui mekanisme demokrasi dan kehidupan demokratis yang sehat, recovery bangsa yang mengalami "peradangan" sosial cukup akut bisa dimulai. Demokrasi dengan transparansi dan akuntabilitas membuka ruang-ruang partisipasi publik untuk melakukan koreksi, pembenahan, dan pembangunan kultur demokrasi demi kemajuan negeri. Di sinilah letak urgensi demokrasi kontekstual: sebuah model demokrasi yang mendorong masyarakat lokal menemukenali sendiri pesan-pesan demokrasi lokal yang dimilikinya. Demokrasi kontekstual juga berarti menjunjung tinggi pluralitas budaya dan agama, karena dari kedua aras itu terbangun sistem nilai dan tata aturan yang dihormati masyarakat. Demokrasi kontekstual, pada akhirnya, juga bermakna pengakuan terhadap identitas dan elemen-elemen simbolik lokal: tatanan, struktur, hingga kepada tokohtokoh lokal.

Dari alas kesadaran itulah Program Sekolah Demokrasi di Jeneponto (SDJ) dilaksanakan. Sebuah program pendidikan politik-demokrasi warga yang terselenggara atas dukungan penuh dari Komunitas Indonesia untuk Demokrasi (KID) kerjasama Netherlands Institute for Multiparty Democracy (NIMD). Artikel ini dimaksudkan menggambarkan secara bernas program tersebut, khususnya di tingkat lokal Jeneponto. 


\section{SDJ dan Kesadaran Kritis Warga}

Program Sekolah Demokrasi Jeneponto (SDJ) secara umum bertujuan menumbuhkan kultur demokrasi di kalangan muda strategis melalui sebuah mekanisme pendidikan politik yang berbasis kepada kepentingan rakyat. Mengapa melalui pendidikan rakyat? Karena pendidikan adalah jalan utama untuk memperkuat kesadaran tentang bagaimana implementasi demokrasi kerakyatan itu dibangun. Pendidikan politik bagi kaum muda strategis dipandang penting karena dapat menjadi wadar bagi anak-anak muda yang begitu antusias dan takjub akan perubahan politik yang tengah berlangsung. Sebelum mereka memutuskan untuk "terjun bebas" dalam kancah politik-demokrasi mereka dituntut memiliki bekal yang memadai baik secara teoretis-konseptual maupun praktis.

Pada tataran teoretis SDJ mengenalkan konsep demokrasi dari berbagai aliran pemikiran. Varian-varian demokrasi diperkenalkan dengan menitikberatkan pada setting sosial ketika ide itu tumbuh. Tidak ada sebuah gagasan lahir tanpa dipengaruhi oleh realitas sosial-politik yang beredar di sekelilingnya. Realitas konflik maupun dinamika ekonomi, sosial, dan budaya menjadi elemen penting untuk melihat bagaimana nilai demokrasi itu dibentuk.

Karena itu, pada tataran teoretis ini pula perlu dikembangkan ragam perspektif yang kini menjadi domain penting dunia pergerakan. Perspektif feminisme misalnya akan memberikan penajaman bagaimana proses eksploitasi berjalan dan menyentuh kalangan perempuan. Hal yang sama dengan perspektif kearifan lokal akan tampak bagaimana kolonisasi dan "penyeragaman" kebudayaan adalah bagian inti dari kesewenang-wenangan kekuasaan negara. Perspektif teoretis yang berbasis pada pengakuan HAM akan menempatkan nilai kemanusiaan pada dimensi yang lebih empirik, terutama konteks pelanggaran hak ekonomi, sosial, dan budaya.

Sementara pada tataran praktis, SDJ lebih menekankan bagaimana peserta memahami sebuah proses demokrasi yang tengah berlangsung di lapangan. Di sini peserta dapat menyentuh secara langsung bagaimana rakyat memahami demokrasi. Pendidikan yang menerjunkan kaum aktivis ke lapangan menjadi penting, karena sentuhan akan realitas dapat membuat pengetahuan demokrasi menjadi sesuatu yang kongkret. Realitas ekonomi dan politik yang timpang akan melahirkan paras demokrasi yang memiliki visi populis serta daya sentuh yang kuat dan berpihak pada rakyat. Pendidikan yang menonjolkan aspek praksis ini pada urutannya memberikan bekal bagi para peserta SDJ untuk mendesain organ gerakan simpul demokrasi lokal yang memiliki akar kuat di tangan rakyat.

Secara, khusus peserta program SDJ bertujuan: pertama, memberikan wawasan kritis tentang hak politik dan hak-hak sipil warga meliputi: masyarakat akar rumput, aktivis parpol, pelaku bisnis, lembaga politik, anggota parlemen (DPRD), dan kekuatan civil society lainnya untuk lebih memahami hak-hak rakyat, keadilan sosial, ekonomi, dan politik, pengawasan pembangunan, proses pembuatan kebijakan dan gerakan advokasi anti korupsi untuk mendukung reformasi.

Kedua, memberikan soft skills dan kemampuan teknis kepada peserta yang memungkinkan untuk berpartisipasi dalam proses pembuatan kebijakan publik yang berpihak kepada rakyat, responsif terhadap isu-isu demokrasi, gender, HAM, dan mendukung gerakan anti korupsi. Ketiga, mendisain cikal bakal Komite Komunitas (KK) melalui kultur jaringan dan gerakan perubahan yang dilakukan secara bersama guna melahirkan tata pemerintahan lokal serta sistem politik demokratis, berpespektif gender, HAM, dan anti korupsi. 
Sementara itu, sasaran dan target group program SDJ adalah:

- Interaksi antar-pranata (inter-institutional interaction) diantara 4 pranata utama, yaitu lembaga politik, politisi, komunitas bisnis, dan rakyat (civil society).

- Peserta sekolah demokrasi adalah orang-orang muda yang diharapkan bisa meningkatkan kualitas wacana kritis dalam keempat pranata tersebut untuk perluasan partisipasi politik menuju masyarakat yang demokratis.

\section{Mengapa Memilih Sekolah Demokrasi di Jeneponto}

Sulawesi Selatan, sebagai salah satu provinsi di Indonesia juga memiliki prinsipprinsip filosofis demokrasi yang berakar-dalam pada tradisi yang cukup panjang. Dengan demikian sangat memungkinkan terjadinya dialog kreatif antara nilai-nilai demokrasi yang universal itu dengan tradisi dan kearifan lokal masyarakat Sulawesi Selatan, terutama dalam upaya "pembumian" demokrasi yang berbasis nilai lokal, di Jeneponto.

Sebagai salah satu kabupaten di Sulawesi Selatan, Jeneponto termasuk beretnis Makassar. Dengan luas wilayah 74.979 ha, daerah ini terbagi ke dalam 9 kecamatan dan 111 desa/kelurahan. Jumlah pendudukan (2011) sebesar 323.302 jiwa, sedangkan jumlah angkatan kerja 137.538 jiwa (Jeneponto dalam Angka, 2012).

Ada sejumlah alasan mengapa Kabupaten Jeneponto ditunjuk pihak NIMD-KID sebagai lokasi pilot project pengembangan Sekolah Demokrasi di Sulawesi Selatan: (1) daerah lahan kritis; (2) penolakan keras terhadap etnis-keturunan dan agama tertentu; (3) ada gejala premanisme politik; (4) kualitas pendidikan relatif rendah; (5) fenomena praktik pengadilan massa terhadap pelaku kriminalitas; (6) penyelesaian masalah cenderung menggunakan kultur kekerasan; (7) tradisi patriarkhi sangat kuat; (8) simbol-simbol sosial kuat; (9) paham keagamaan yang berkembang di masyarakat cenderung bersifat legalistik-formal dan eksklusif; (10) aroma feodalisme-kultural sangat kental.

Meski demikian Kabupaten Jeneponto memiliki sejumlah kearifan lokal yang masih hidup dan dijunjung tinggi masyarakatnya hingga kini seperti: budaya siri' (malu-harga diri), a'bulo sibatang (kesetiakawanan, keke-rabatan), kultur pesisir yang mencirikan semangat percaya diri dan dinamis terhadap perubahan, sipakatau (saling menghargai), dan sipakainga' (saling menasihati). Nilai-nilai ini jelas sangat positif terutama dalam upaya mendorong proses demokratisasi yang bermartabat di daerah ini.

\section{Disain dan Proses Pebelajaran SDJ}

Berikut ini digambarkan bagaiman disain dan proses pembelajaran SDJ dengan menghadirkan bagan:

\section{Kerangka Pemikiran Proyek}

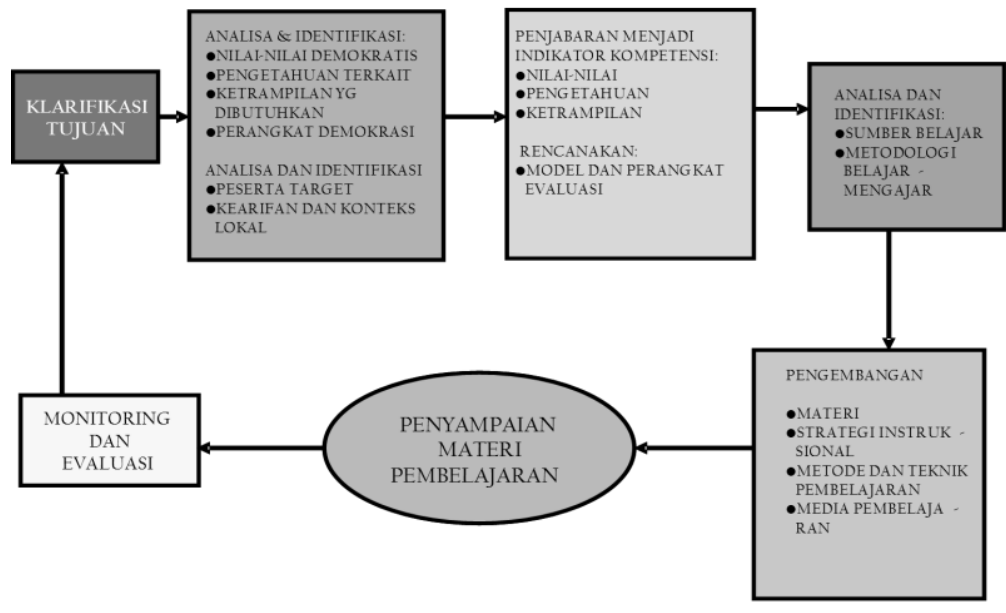




\section{Materi}

Sementara itu, tema-tema pembelajaran tersusun sebanyak 10 (sepuluh) modul yang dikelompokkan ke dalam 8 (delapan) modul Nasional dari KID dan 2 (dua) modul Lokal. Yang termasuk "Modul Nasional" adalah: Perkembangan Pemikiran dan Praktik Demokras, Sistem Pemerintahan dan Politik di Indonesia, Gerakan Sosial, Kebijakan Publik, Konsepsi Demokrasi, Bisnis dan Demokrasi, Legislasi Kebijakan Daerah, dan Analisis Kemasyarakatan. Sementara untuk "Modul Lokal" terdiri atas: Konflik dan Budaya Lokal dan Perencanaan Keuangan Daerah.

\section{Waktu Pelaksanaan}

Waktu pembelajaran SDJ dilakukan setiap hari sabtu dan minggu, atau terkadang hari Rabu sesuai kesepakatan peserta. Setiap pertemuan, berlangsung selama 7 jam, mulai jam 09.00 hingga 16.00. Kegiatan pada malam hari, dalam bentuk dialog dan diskusi kelompok dengan mengangkat tema aktual. Setiap modul dibahas sebanyak empat kali pertemuan yaitu tiga kali pertemuan dalam kelas (in door class) dan satu kali pertemuan di luar kelas (out door class). SDJ berlangsung selama tiga angkatan (2006-2008), masing-masing angkatan menggunakan durasi waktu setahun.

\section{Rekrutmen Narasumber dan Fasilitator}

Narasumber adalah pengajar yang melakukan proses transformasi nilai-nilai, pengetahuan, ketrampilan dan perangkat demokratis kepada peserta SDJ. Fasilitator adalah orang yang mendampingi narasumber dalam kegiatan pembelajaran di dalam kelas dan di luar kelas yang tugasnya melakukan kegiatan praktis untuk menerjemahkan materi pembelajaran ke dalam suasana kongkrit.

Narasumber dan fasilitator berlatar belakang yang beragam: akademisi, tokoh agama dan tokoh masyarakat, aktivis LSM, politisi, pejabat pemerintah, militer, profesional, seniman, budayawan dan wirausahawan dengan syarat yang ditetapkan pihak KID diantaranya: memiliki pengetahuan dan pemahaman mengenai demokrasi yang memadai, memiliki pengalaman dalam praktik demokrasi, memiliki referensi dari kalangan pro demokrasi yang kredibel, berintegritas, serta berkomitmen kuat kepada nilai kebaikan dan kerakyatan. Proses rekrutmen dilakukan melalui pengamatan dan mempertimbangkan rekam jejak narasumber dan fasilitator.

\section{Rekrutmen Peserta}

Peserta atau target group berjumlah 30 orang perangkatan yang diterima melalui proses seleksi yang dilakukan penyemenggara. Hingga berakhirnya program ini pada 2008, tak kurang dari 90 peserta yang ikut terlibat dalam proses pembelajaran.

\section{Training of Trainer (TOT)}

Untuk penyamaan persepsi terhadap SDJ, dilakukan TOT bagi narasumber dan fasilitator. Terhadap narasumber, bentuk TOT dilakuakn dalam bentuk round table discussion, dengan fokus pada dua hal yaitu materi pembelajaran dan strategi pembelajaran. Sedangkan terhadap fasilitator, difokuskan pada metode kegiatan praktis kelas, metode pembelajaran orang dewasa, monitoring dan evaluasi kegiatan belajar. 


\section{Proses Pembelajaran}

Pra Pembelajaran

a. Matrikulasi

Kegiatan matrikulasi merupakan kegiatan awal untuk menyamakan persepsi peserta tentang konsep-konsep dasar materi modul pembelajaran. Setidaknya tingkat pemahaman dasar tentang materi pemelajaran tidak memiliki jarak yang jauh antara satu dengan lainnya. Oleh karena itu, materi matrikulasi secara keseluruhan merupakan materi pengantar sebelum memasuki materi pembelajaran nantinya.

\section{b. Outbound}

Outbound dimaksudkan laksanakan membangun keakraban atau kedekatan antara sesama peserta, peserta dan fasilitator, peserta dan pelaksana. Dengan kedekatan diharapkan akan terbangun komunikasi, interaksi dan kerjasama yang baik antara peserta, fasilitator dan pelaksana, selama program pembelajaran berlangsung.

c. Sosialisasi

Kegiatan sosialisasi dimaksudkan untuk menginformasikan pelaksanaan program Sekolah Demokrasi Jeneponto (SDJ) kepada masyarakat secara umum dan pemerintah setempat. Dengan kegiatan ini diharapkan masyarakat dapat mengetahui dan lebih memahami maksud penyelenggaraan Program. Peserta kegiatan sosialisasi ini adalah para peserta program dan para undangan dari berbagai unsur masyarakat Jeneponto dan Pemerintah baik eksekutif, legislatif maupun yudikatif.

Pembelajaran

Kegiatan di Dalam Kelas

a. Ceramah Tatap Muka

Ceramah tatap muka merupakan kegiatan penyampaian informasi pembelajaran dari narasumber kepada peserta pembelajaran. Penyampaian dilakukan dalam bentuk ceramah. Materi yang disampaikan berasal dari modul mata pelajaran yang sama dimiliki oleh peserta pembelajaran. Kegiatan ini berlangsung antara 30-45 menit.

\section{b. Tanya-jawab}

Proses tanya-jawab berlangsung antara peserta dengan nara sumber. Peserta bertanya dan narasumber menjawab. Kegiatan ini dilakukan setelah ceramah tatap muka selesai disampaikan atau dapat juga berlangsung selama kegiatan ceramah. Kegiatan ini dipandu oleh fasilitator dan berlangsung antara 45-60 menit. Seluruh pertanyaan dan jawaban terdokumentasikan dalam bentuk proceeding oleh notulen yang ditunjuk.

c. Diskusi Terstruktur

Diskusi terstruktur adalah sebuah diskusi yang dilakukan secara berkelompok, mengangkat sebuah tema, dipandu oleh fasilitator dengan seorang narasumber sebagai pembicara utama. Metode diskusi diperkaya dan diperluas secara kreatif sehingga tidak membosankan. Salah satu contoh adalah model interaktif, teatrikal dan sebagainya. 


\section{d. Penugasan}

Penugasan merupakan kegiatan yang diberikan oleh narasumber atau fasilitator kepada peserta pembelajaran yang dilakukan di dalam kelas atau dikerjakan di rumah. Bentuk-bentuk penugasan dapat bermacam-macam dan dilakukan secara kreatif. Salah satu contoh adalah peserta mengemukakan sebuah peristiwa ril di masyarakat yang demokratis dan tidak demokratis menurut pandangan peserta.

e. Permainan

Permainan merupakan salah satu media pembelajaran yang mentransformasikan sebuah peristiwa atau obyek ke dalam sebuah kegiatan ril yang dikemas dalam bentuk permainan simulasi. Peserta bertindak sebagai obyek sekaligus subyek dan berusaha menemukan makna dari sebuah permainan. Substansi kegiatan ini adalah pada proses permainan yang dilakoni dan berada pada suasana pembelajaran yang fun.

\section{Kegiatan di Luar Kelas}

a. Ceramah tatap muka di tempat tertentu

Sejauh ini, kegiatan pembelajaran di luar kelas dilakukan pada berbagai tempat sesuai dengan rancangan yang telah dibuat. Tempat tersebut antara lain; gedung DPRD Jeneponto, kantor Camat, kantor Kepala Desa, masjid, rumah seorang tokoh, Balai Desa, Pasar, Pelabuhan Pelelangan Ikan, Kantor Parpol, sekolah dan sebagainya. Interaksi terjadi antara peserta pembelajaran dengan obyek. Narasumber berasal dari berbagai tokoh; DPRD, kepala desa, pemuka agama, tokoh adat, pelaku bisnis dan lain-lain. Metode penyampaian antara lain tudang sipulung, abbulosibatang, Paccarita, Petta-Puang, Baco-puraga (wayang orang a-la makassar), sinrilik.

b. Pengamatan Atas Obyek/Peristiwa Demokrasi

Pengamatan ini dilakukan terhadap suatu obyek atau peristiwa yang dilakukan oleh orang atau sebuah institusi yang mengungkapkan sebuah proses demokrasi. Peserta diharapkan dapat mengamati proses tersebut dan menuangkannya dalam sebuah laporan dan mendiskusikannya. Peristiwa tersebut antara lain proses rapat di DPRD, transaksi di pasar, proses penentuan calon legislatif di Parpol, proses pemilihan kepala desa, praktik pelayanan masyarakat pada sektor-sektor publik, dan sebagainya. Posisi peserta pembelajaran sebagai pengamat atas peristiwa tersebut, kemudian mendiskusikannya dengan sesama peserta.

c. Observasi lapang terstruktur

Kegiatan ini dilakukan secara mandiri oleh peserta pembelajaran. Peserta memilih suatu obyek tertentu kajian demokrasi di desanya kemudian melakukan pengamatan selama waktu tertentu (sekitar 1 bulan). Metode observasi lapang yaitu peserta melakukan interaksi, dialog, wawancara, dan keterlibatan langsung dengan masyarakat dalam sebuah proses demokrasi. Setelah itu menyusun laporan dan mempresentasikan di hadapan kelas pembelajaran.

\section{d. Pemutaran dan Diskusi Film Bertemakan Demokrasi}

Kegiatan pemutaran film dilakukan di dalam ruangan atau di lapangan. Film-film yang diputar bertemakan demokrasi, kemanusiaan, gerakan sosial, hukum \& HAM, kebebasan, politik, ekonomi, bisnis dan sebagainya. Setelah pemutaran, peserta SDJ 
mendiskusikannya secara berkelompok kemudian mempresentasikannya. Kegiatan ini dipandu fasilitator dan juga menghadirkan narasumber bedah film.

e. Pertunjukan Seni Demokrasi

Kabupaten Jeneponto dan Sulawesi Selatan umumnya, sangat kaya dengan tradisi seni budaya yang banyak menggambarkan sebuah prosesi demokrasi dalam berbagai aspek kehidupan. Pentas seni (art show), sebab itu dijadikan media penyampai pesan-pesan nilai demokrasi. Kegiatan ini dilakukan di dalam ruangan atau pun di lapangan terbuka. Peserta pembelajaran diminta mengamati lakon dramatik prosesi itu kemudian mendiskusikannya, menulis resume dan mempresentasikannya.

\section{f. Talkshow}

Kegiatan talkshow dilakukan oleh peserta di radio lokal Jeneponto Sipitangarri dan Mercury FM di Makassar. Materi yang dibincangkan seputar tema pembelajaran dan topiktopik yang hangat di masyarakat. Kompoisi narasumber empat orang yang terdiri atas tiga orang narasumber dari peserta SDJ dan satu orang narasumber lokal. Kegiatan ini disiarkan secara live dan dialog interakti dengan masyarakat.

\section{Komite Komunitas: Alumni dan Jejaring Pro Demokrasi}

Para alumni SDJ (2006-2008), menginisiasi tebentuknya "Komite Komunitas". Sebuah wadah non formal bagi perjumpaan wacana tidak saja di antara mereka tetapi juga masyarakat secara luas dalam rangka mendorong akselerasi terbentuknya civil society. Para alumni tersebut kini tersebar ke dalam lini kehidupan: anggota legislatif, pengurus partai politik, PNS, aktivis LSM, ormas, dan seterusnya. 


\section{DAFTAR PUSTAKA}

----------,"Masalah Kebudayaan dalam Pembangunan" dalam Jurnal Humaniora, Vol. XV.

Abdullah, Irwan. 1999. Bahasa Nusantara: Posisi dan Perkembangannya di Abad ke-21, Yogyakarta: Pustaka Pelajar.

Arief, Sritua. 1990. Dari Prestasi Pembangunan sampai Ekonomi Politik, Jakarta: UI Press.

Berger, Peter dan Thomas Luckmann. 1979. The Social Construction of Reality, New York: Penguin Books.

Dzuhayatin, Ruhaini dan Kumala Sari, 2006. HAM dan Demokrasi, Jakarta: KID

Falaakh, Fajrul, 2006. Legislasi Daerah dan Hukum, Jakarta: KID

Hardjono, Ratih dan Anita Lie, 2006. Demokrasi dan Bisnis, Jakarta: KID

Haryati, Eny, 2006. Kebijakan Publik, Jakarta: KID

Hertz, Noreena. 2002. The Silent Takeover: Global Capitalism and the Death of Democracy.

Kleden, Ignas dan Daniel Sparringa, 2006. Konsepsi Demokrasi, Jakarta: KID

Korten, David C, 1988, "Pembangunan yang Berpusat pada Rakyat: Menuju suatu Kerangka Kerja" dalam D.C. Korten \& Sjahrir (ed.), Pembangunan Berdimensi Kerakyatan. Jakarta: Yayasan Obor Indonesia.

Madjid, Nurcholish, 1999. “Indonesia Menuju Masa Depan”, Makalah.

Nugroho, Heru, 2006. Analisis Kemasyarakatan, Jakarta: KID

Sabri AR, Mohd dan Idrus Taba (Eds), 2007. Demokrasi Kontekstual: Esai-Esai Pemikiran, Jakarta: KID-Melania Foundation.

Sanit, Arbi, Rahman Tolleng dan Ichlasul Amal, 2006. Sistem Politik dan Pemerintahan, Jakarta: KID

SKN-KID, 2006. Pedoman Pelaksanaan Sekolah Demokrasi, Jakarta: KID

Soetrisno, Loekman. 1988. "Pembangunan Ekonomi dan Demokratisasi Ekonomi: satu Perspektif Sosiologis," dalam Prisma, Vol. 17, No.6.

Suharko, 2006. Gerakan Sosial, Jakarta: KID.

Wekke, Ismail Suardi, and Maimun Aqsha Lubis. "A Multicultural approach in Arabic language teaching: creating equality at Indonesian pesantren classroom life." Sosiohumanika 1, No. 2, 2016.

Wekke, Ismail Suardi. "Islam dan Adat dalam Pernikahan Masyarakat Bugis di Papua Barat." THAQAFIYYAT: Jurnal Bahasa, Peradaban dan Informasi Islam 13, No. 2, 2014.

Wekke, Ismail Suardi. "Islam dan adat: tinjauan akulturasi budaya dan agama dalam masyarakat Bugis." Analisis: Jurnal Studi Keislaman 13, No. 1, 2017: 27-56.

Wignjosoebroto, Soetandyo, 2006. Perekmbangan Pemikiran dan Praktik Demokrasi, Jakarta: KID. 